\title{
A Comparative Study between Staplers and Suture (Silk 2-0) for Skin Closure in Cesarean Sections at Gandaki Medical College Teaching Hospital
}

\author{
Jahan $\mathrm{K}^{1^{*}}$, Shrestha $\mathrm{R}^{2}$, Adhikari $\mathrm{P}^{3}$, Tripathi $\mathrm{M}^{4}$, \\ Neupane $\mathrm{CP}^{5}$, Gurung $\mathrm{RT}^{2}$, Gurung $\mathrm{TK}^{2}$, Mally $\mathrm{J}^{2}$ \\ ${ }^{1}$ Assistant Professor, ${ }^{2}$ Lecturer, ${ }^{3}$ Intern, ${ }^{4}$ Professor \& Head, ${ }^{5}$ Associate Professor \\ Department of Obstetrics and Gynecology, Gandaki Medical College \& Teaching Hospital, Pokhara, Nepal
}

\section{Keywords \\ Cesarian section, Skin closure, Stapler, Suture.}

\section{Corresponding author \\ *Dr. Kamar Jahan \\ Assistant Professor \\ Department of Obstetrics and \\ Gynecology \\ Gandaki Medical College \& Teaching \\ Hospital, Pokhara, Nepal \\ Email: ayaazkamar@gmail.com}

\begin{abstract}
Background: Skin closure in the abdominal surgeries is an important factor that affects the prognosis of wound in terms of hospital stay as well as overall outcome of the surgery.
\end{abstract}

Objectives: Cesarean section being the commonly performed operation, choice of suture material has the unexceptional role on it. This study has been performed with an objective to look for the merits and demerits of the skin closure by suture (Silk 2-0) and stapler.

Methods: Prospective comparative study conducted among the patients admitted in a Maternity Ward of Gandaki Medical College Teaching Hospital for elective and emergency cesarean section. The comparison has been made in terms of time taken during the skin closure, presence or absence of soakage and wound dehiscence, day of suture removal and pain during the suture removal.

Results: The average time taken for skin closure for suture group was found to be $5.46 \mathrm{~min}( \pm 0.97)$ and the same for stapler group was found to be 1.22 min $( \pm 0.15)$ respectively. Similarly, the mean day of stitch removal in suture and staples were found to be $6.94( \pm 1.75)$ and 7.95 $( \pm 1.89)$ respectively. Surgical site infection (SSI) i.e. soakage was present in eight percent of those in suture group and $20 \%$ in stapler group. Wound dehiscence was present in two percent among the suture group and five percent among the stapler group. The severity of pain is more in stapler group than that of suture group during its removal.

Conclusions: Our study concluded suture being superior to staplers for skin closure during cesarean section. Though time taken for the closure is less in the stapler group, other factors like wound complications, duration of hospital stay, pain during its removal favored for the suture to be used.

wish to see wound healthy and scar cosmetically better. The method of closure should be simple, quick to use and cost effective. Many factors are involved in the choice of the skin closure material, including the type and place of the wound, available materials, physician expertise and preferences, patient age and health ${ }^{2}$. 
Cesarean section is one of the most commonly performed abdominal surgeries worldwide with recent increase to unprecedented levels ${ }^{3}$. Mostly obstetricians use staples, interrupted suture or subcuticular suture immediately below the skin layer to close the skin during cesarean section $^{4}$. The choice of the suture materials may affect the overall prognosis of wound in terms of time taken for skin closure, duration of hospital stay, wound infection, pain during the suture removal cosmetic outcome of the scar $^{5}$. The existing literature still does not provide enough evidence to say whether one of the suture material either staplers or suture is better than one another for closure of abdominal wall in cesarean section ${ }^{6}$.

This comparative study has been done with objective to see the merits and demerits of skin closure by stapler and suture. The comparison has been made in terms of time taken during the skin closure, presence or absence of soakage and wound dehiscence, day of suture removal and pain during the suture removal.

\section{METHODS}

Study design: Prospective comparative study conducted among the patients at Medical College Teaching Hospital of Western Region of Nepal.

Study site: Gandaki Medical College Teaching Hospital

Study population: The admitted patients in the Maternity Ward who went for elective or emergency cesarean section and agreed to participate were included in the study.

Sample size: In this study 200 pregnant women of aged 16 to 36 were enrolled.

Study Period: $15^{\text {th }}$ April, 2016 to $14^{\text {th }}$ May, 2017

Sampling procedure: Convenience sampling was applied as the patients admitted in Maternity Ward for cesarean section during the period of April 2016 to May 2017 were enrolled in the study.

Instruments and techniques: The patients were divided into two groups on the basis of material used for skin closure in cesarean section i.e. stapler and suture.

Suture group: Skin was approximated with vertical mattress suture using non absorbable silk 2-0 at a distance of one $\mathrm{cm}$ from each other.

Stapler group: The staplers were used to close the wound placed at a distance of $5 \mathrm{~mm}$ from one another.

Each patient was given same antibiotics for the same duration. Wound of every patient was assessed at fourth, sixth, seventh and eighth post operative day. Wound dehiscence was noted.

Pain occurring during the removal was evaluated as mild, moderate or severe as described by the patient on 3 point severity scale.

Data analysis: Data was entered in SPSS 18 software and analyzed. Proportions, percentage were calculated for descriptive statistics and Chi square test was performed for the statistical analysis of the observations. P-value was set at 0.05 level of significance.

Ethical consideration: Informed consent for the enrollment in study was taken for all the patients before the surgery. Ethical clearance was taken and the ethical approval was obtained from the Institutional Ethical Committee of Gandaki Medical College.

\section{RESULTS}

Total 200 cases studied were divided into two groups each of 100 cases. Those cases whose skin was closed with suture are categorized as "Suture group" and those with stapler are categorized in "Stapler group" to compare the time taken during the skin closure, presence or absence of soakage and wound dehiscence, day of suture removal and pain during the suture removal. The results were analyzed from the observations made as follows:

\section{1. Age distribution}

The mean age of the participants in the suture group and stapler group were $24.12( \pm 4.073)$ and $24.74( \pm 4.769)$ respectively. The age wise distribution of the two different groups is shown in fig 1.

Fig 1: Age wise distribution of suture and stapler groups

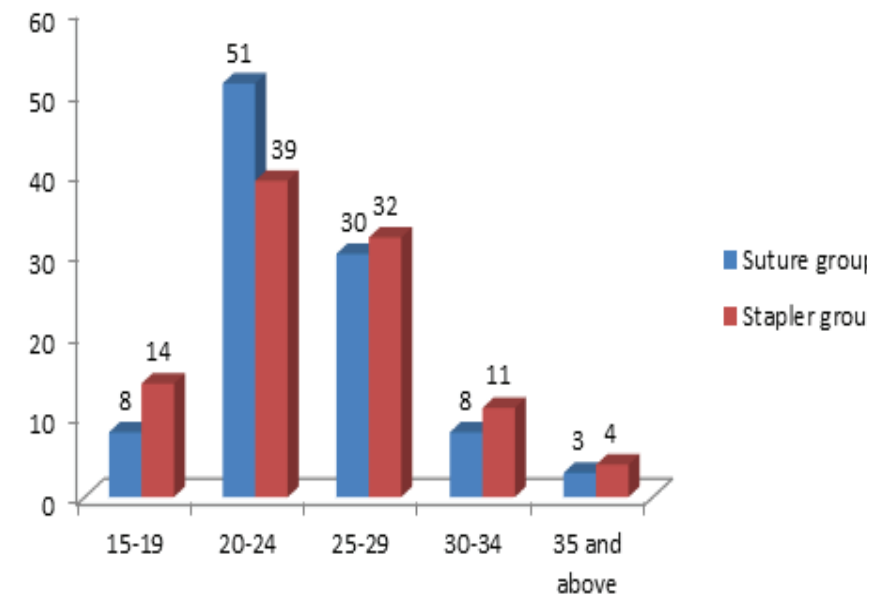




\subsection{Time taken for skin closure}

The average time taken for skin closure for suture group was found to be $5.46 \mathrm{~min}( \pm 0.97)$ and the same for stapler group was found to be $1.22 \mathrm{~min}( \pm 0.15)$ respectively $(\mathrm{p}<0.001)$.

\subsection{Day of stitch removal}

The mean day of stitch removal in suture and stapler were found to be $6.94( \pm 1.75)$ and $7.95( \pm 1.89)$ respectively $(\mathrm{p}<0.001)$.

\subsection{Surgical site infection (Soakage)}

Surgical site infection (SSI) i.e. soakage was present in eight percent of those in suture group and 20\% in stapler group ( $\mathrm{p}=0.014)$ as shown in table 1 .

Table 1: Surgical Site Infection in suture and stapler group

\begin{tabular}{lccccc}
\hline \multirow{2}{*}{$\begin{array}{c}\text { Surgical Site } \\
\text { Infection }\end{array}$} & \multicolumn{2}{c}{ Group A } & \multicolumn{2}{c}{ Group B } & \multirow{2}{P}{} \\
\cline { 2 - 5 } & $\mathbf{N}$ & $\mathbf{\%}$ & $\mathbf{N}$ & $\mathbf{\%}$ & value \\
\hline Present & 8 & 2 & 20 & 20 & \\
Absent & 92 & 98 & 80 & 80 & 0.014 \\
\hline
\end{tabular}

\subsection{Wound dehiscence}

Wound dehiscence was present in two percent among the suture group and five percent among the stapler group ( $\mathrm{p}=0.248)$ as shown in table 2 .

Table 2: Wound dehiscence in suture and stapler group

\begin{tabular}{llllll}
\hline \multirow{2}{*}{$\begin{array}{c}\text { Wound } \\
\text { dehiscence }\end{array}$} & \multicolumn{2}{c}{ Group A } & \multicolumn{2}{c}{ Group B } & \multirow{2}{*}{ P value } \\
\cline { 2 - 5 } & $\mathbf{N}$ & $\mathbf{\%}$ & \multicolumn{1}{c}{$\mathbf{N}$} & \multicolumn{1}{c}{$\%$} & \\
\hline Present & 2 & 2 & 5 & 5 & 0.248 \\
Absent & 98 & 98 & 95 & 95 & \\
\hline
\end{tabular}

\subsection{Pain during stitch removal}

The severity of pain is more in stapler group than that of suture group during its removal as shown in table 3.

Table 3: Pain during stitch removal

\begin{tabular}{lccccc}
\hline \multirow{2}{*}{ Severity } & \multicolumn{2}{c}{ Group A } & \multicolumn{2}{c}{ Group B } & P value \\
\cline { 2 - 5 } & $\mathrm{N}$ & $\%$ & $\mathrm{~N}$ & $\%$ & \\
\hline $\begin{array}{l}\text { Mild } \\
\text { Moderate and }\end{array}$ & 94 & 94 & 74 & 74 & \\
Severe & 6 & 6 & 26 & 26 & 0.000 \\
\hline
\end{tabular}

\section{DISCUSSION}

Every surgeon wishes for the early healing of post operative wound with minimal complications. Indeed, it's the responsibility of the surgeon to choose the method of skin closure that would be suitable for the patient in terms of early wound healing without post operative surgical site infection, cost effectiveness, minimal pain during the suture removal and duration of hospital stay. In our study, the two groups with similar demographic characteristics are evaluated with skin closure by suture on one and stapler on other.

In our study, time taken for the skin closure by staplers was significantly less than by suture which is in consistent with the other studies ${ }^{7-10}$. Use of staplers will thus shorten the duration of surgery and anesthesia on the patients considerably reducing the perioperative risk. It will also be of great value in the busy obstetric care settings where high number of patients needs to undergo cesarean section.

The mean day of stitch removal in suture group was found to be earlier than that of stapler which was statistically significant $(\mathrm{p}<0.001)$. This may be due to the fact that less evidence of surgical site infections was seen in the patient with suture group. This favors for the early discharge of patient from the hospital and indeed results in decrease in post operative complications. Similar study conducted by Basha et al ${ }^{9}$ showed no significant difference between two groups in the length of hospital stay.

As far as surgical site infections i.e. soakage of the wound is concerned, it was seen more in the patient with stapler group than that of suture which was statistically significant $(p=0.014)$. Similarly the wound dehiscence was also found to be more on the patient with stapler group that of suture $(\mathrm{p}=0.248)$. The findings of our study were consistent with the studies by Mackeen et $a l^{5}$ and Basha et $a l^{9}$ where wound complication rates were higher in stapler group. A meta-analysis of randomized control trails by Clay et $a l^{11}$ comparing staples and subcuticular suture had also shown high wound complications rate in staples group than that of suture. The exact reason behind the high infection rates among the staples group is not clear. We hypothesize that it may be due to increased bacterial migration to the incision site because of the gap between staples. Furthermore studies are needed to make this understanding clear.

Similarly, our study suggests the severity of pain is more in staples group than that of suture group during its removal. This finding is consistent with other studies conducted in orthopedic surgeries ${ }^{12,13}$, where the patient reported more pain during the stapler removal than that of suture. The reason for this may be more traumatic and 
rigid fixation of the tissues by staplers.

Another important factor to be discussed here is the cost effectiveness of the suture and staplers for the abdominal closure. The market price of the staplers is relatively more than that of suture used for the abdominal wound closure here in our settings. Similar finding has been demonstrated in the study by Abdus-Salam et $a \Gamma^{7}$.

The limitation of our study is that we didn't evaluate other parameters for the comparison between the stapler and suture like patient satisfaction and scar cosmetic outlook after the healing. Other studies ${ }^{10,14}$ that evaluated these parameters also didn't find any significant differences on it among the stapler and suture group.

The results of our study advocated for the use of suture rather than staplers during cesarean section for the skin closure. Though time taken for the closure is less in the stapler group, other factors like wound complications, duration of hospital stay, pain during its removal favored for the suture to be used. The cost effectiveness among the two is also an important factor determining for the selection of stapler and suture in our resource limited settings which furthermore emphasized for the use of suture rather than staplers.

\section{CONCLUSIONS}

We compared the merits and demerits of the stapler and suture based on the different parameters. Staplers are less time consuming but have high rate of wound complications, results in lengthy duration of hospital stay and more painful during its removal. Furthermore staplers are expensive than suture. Our study provided the baseline comparison of outcomes between the staplers and suture for the skin closure in the cesarean section. Furthermore it's the choice of the operating surgeon and availability of the suture or staplers that ultimately decides the selection of suture materials for the skin closure in cesarean section.

\section{Acknowledgement}

The authors would like to express their sincere gratitude to all the faculties of Department of Obstetrics and Gynecology of Gandaki Medical College Teaching Hospital for their valuable support to conduct the study during the whole period. Similarly, we express heartfelt thanks to Prof. Dr. Ishwari Sharma Paudel who helped in the statistical analysis and all the participants of the study who gave consent to be enrolled in the study.

\section{REFERENCES}

1. Mackenzie D. The history of sutures. Medical History. 1973; 17(2): 158-68.

2. Al-Mubarak L, Al-Haddab M. Cutaneous wound closure materials: An overview and update. Journal of Cutaneous and Aesthetic Surgery. 2013; 6(4): 178-88.

3. Betran AP, Ye J, Moller AB, Zhang J, Gulmezoglu AM, Torloni MR. The increasing trend in caesarean section rates: Global, regional and national estimates: 19902014. PLoS One. 2016; 11(2): e0148343.

4. Mackeen AD, Berghella V, Larsen M-L. Techniques and materials for skin closure in caesarean section. Cochrane Database of Systematic Reviews. 2012; (9).

5. Mackeen AD, Khalifeh A, Fleisher J, Vogell A, Han C, Sendecki J et al. Suture compared with staple skin closure after cesarean delivery: A randomized controlled trial. Obstet Gynecol. 2014; 123(6): 116975.

6. Anderson ER, Gates S. Techniques and materials for closure of the abdominal wall in caesarean section. Cochrane Database Syst Rev. 2004; (4): CD004663.

7. Abdus-Salam RA, Bello FA, Olayemi O. A randomized study comparing skin staples with subcuticular sutures for wound closure at caesarean section in black-skinned women. Int Sch Res Notices. 2014; 2014: 807937.

8. S. S. Karbhari, Avinash K. Bhavikatti. Study of skin staples and conventional sutures for abdominal skin wound closure. International Journal of Biomedical and Advance Research. 2012; 03(07): 552-4.

9. Basha SL, Rochon ML, Quinones JN, Coassolo KM, Rust OA, Smulian JC. Randomized controlled trial of wound complication rates of subcuticular suture vs staples for skin closure at cesarean delivery. Am J Obstet Gynecol. 2010; 203(3): 285 e1-8.

10. Rousseau JA, Girard K, Turcot-Lemay L, Thomas N. A randomized study comparing skin closure in cesarean sections: Staples vs subcuticular sutures. Am J Obstet Gynecol. 2009; 200(3): 265 e1-4.

11. Clay FS, Walsh CA, Walsh SR. Staples vs subcuticular sutures for skin closure at cesarean delivery: A metaanalysis of randomized controlled trials. Am J Obstet Gynecol. 2011; 204(5): 378-83.

12. Slade Shantz JA, Vernon J, Morshed S, Leiter J, Stranges 
G. Sutures versus staples for wound closure in orthopaedic surgery: A pilot randomized controlled trial. Patient Saf Surg. 2013; 7 (1): 6.

13. Yuenyongviwat $V$, Iamthanaporn $K$, Hongnaparak $T$, Tangtrakulwanich B. A randomised controlled trial comparing skin closure in total knee arthroplasty in the same knee: Nylon sutures versus skin staples. Bone and Joint Research. 2016; 5(5): 185-90.

14. Gaertner I, Burkhardt T, Beinder E. Scar appearance of different skin and subcutaneous tissue closure techniques in caesarean section: A randomized study. Eur J Obstet Gynecol Reprod Biol. 2008; 138(1): 29-33. 